\title{
RELEITURA E DEBATE CRÍTICO: CURRÍCULO, CONHECIMENTO E CULTURA DA POLÍTICA DE EDUCAÇÃO BRASILEIRA
}

\author{
Juliana de Aquino Fonseca Doronin" \\ Giovanna de Aquino Fonseca Araujo** \\ Amanda Boza Gonçalves Carvalho****
}

RESUMO: O objetivo do texto consiste no debate crítico da atual política educacional brasileira vinculada ao projeto neoliberal que possuí influência da política internacional e seus desdobramentos, com destaque para o currículo, conhecimento e a cultura. A metodologia utilizada foi a revisão bibliográfica e análise crítica do documento ministerial intitulado "Indagações sobre Currículo: currículo, conhecimento e cultura", elaborado por Moreira e Cadau (2007). Realizamos estudo do texto trazendo discussões e reflexões de autores da educação e releituras de documentos específicos como o "Relatório Delors"; RCNEI; PCN's e outros que serviram de aporte teórico e documentais para análise do citado documento ministerial. As análises partiram da percepção da identificação de mensagens trazidas nos termos utilizados na redação do relatório que ilustram diversas contradições e / ou conflitos conceituais, peculiares do projeto Neoliberal vigente em nosso país, a partir dos anos 90. Isso se evidencia, por exemplo, quando a política de educação defende a necessidade de respeito à diversidade para superação das desigualdades, sem refletir sobre os fatores causais de tais desigualdades, corroborando, portanto, com a manutenção dessa desigualdade, uma vez que utilizam termos como "coesão social", no qual sabemos que não é sinônimo de "luta das desigualdades", pelo contrário; ela é possibilidade de naturalização das desigualdades. Concluímos, que apesar dos especialistas elaboradores do texto analisado proporem reflexões para "um novo currículo", acabam por reiterar o que já está posto pelos organismos internacionais, uma vez que trazem as proposições da política educacional com suas incoerências e contradições conceituais.

PALAVRAS-CHAVE: Educação; Desigualdade; Coesão social; Política de educação; Projeto neoliberal.

\footnotetext{
"Doutoranda em Ciências Sociais PUCSP. Docente na Universidade Estadual do Paraná (UNESPAR), Paranavaí (PR), Brasil. E-mail: julianadoronin@hotmail.com

*Pós-doutoranda em História pela Universidade Federal de Campina Grande. Docente da Unifavip Devry, Caruaru (PE), Brasil

${ }^{* * *}$ Mestre em Serviço Social e Política Social pela Universidade Estadual de Londrina (PR). Docente do curso de Serviço Social da UNOPAR, Brasil.
} 


\title{
REREADING AND CRITICAL DEBATE: CURRICULUM, KNOWLEDGE AND CULTURE OF BRAZILIAN EDUCATIONAL POLICY
}

\begin{abstract}
A critical debate on current Brazilian educational policy is forwarded through a bibliographical review and a critical analysis of the Educational Ministry's document titled 'Investigations on the Curriculum: curriculum, knowledge and culture", by Moreira and Cadau (2007). The policy is linked to the neoliberal project influenced by international policies and developments, especially with regard to curriculum, knowledge and culture. The text was analyzed through discussions and debates by educational authors and rereading of specific documents, such as the Report Delors, RCNEI, PCN and others that foregrounded theoretically the above mentioned ministerial document. Analyses comprised the identification of messages in the report on several conceptual contradictions and/or conflicts inherent to the neoliberal project executed in Brazil since the 1990s. This may be seen when educational policy defends respect to diversity to overcome inequalities without discussing the causes of inequalities. This boils down to the fact that it is corroborating with the maintenance of inequality. For example, the term 'social cohesion' is not synonymous with 'the struggle against inequalities'. On the contrary, it may even naturalize inequalities. Results show that, although the authors of the text propose investigations for a 'new curriculum', they repeat what has already been posited by international organisms. In fact, they bring propositions of educational policy with their non-coherences and conceptual contradictions.
\end{abstract}

KEY WORDS: Education; inequality; Social cohesion; Education policy; Neoliberal project.

\section{INTRODUÇÃO}

O artigo 210 da Constituição Federal de 1988 determina como dever do Estado para com a educação, fixar "conteúdo mínimos para o Ensino Fundamental, de maneira a assegurar a formação básica comum e respeito aos valores culturais e artísticos, nacionais e regionais". Nesse sentido, foram elaborados e distribuídos pelo MEC, a partir de 1995, os Referenciais Curriculares Nacionais para a Educação Infantil/ RCNEI, os Parâmetros Curriculares Nacionais/PCN's para o ensino fundamental, e os referenciais curriculares para o ensino médio. Posteriormente, o Conselho Nacional de Educação definiu as diretrizes curriculares para a educação básica. 
Foram elaborados cinco cadernos, tendo como eixos norteadores os seguintes temas: 1- Currículo e Desenvolvimento Humano; 2- Educandos e Educadores: seus Direitos e o Currículo; 3- Currículo, Conhecimento e Cultura; 4- Diversidade e Currículo; 5- Currículo e Avaliação. Tais cadernos têm à intenção de subsidiar a análise das propostas pedagógicas dos sistemas de ensino e dos projetos pedagógicos das unidades escolares de cada município, visando, portanto, uma unidade em nível nacional sem muitas divergências.

Os referidos cadernos se materializaram em documento ministerial intitulado "Indagações sobre Currículo: currículo, conhecimento e cultura", objeto de nossa revisão deste artigo -. O citado documento, foi publicado em 2007, pelo Departamento de Políticas de Educação Infantil e Ensino Fundamental- DPE, vinculado à Secretaria de Educação Básica - SEB, deste Ministério da Educação MEC. Foi elaborado com intenção de desencadear discussões nas escolas e suas representações (GT Currículo, UNDIME, CONSED, SEESP/MEC, SECAD/MEC, CONPEB/MEC, REDE/MEC), sobre a concepção de currículo e seu processo de elaboração por meio das contribuições e discussões de diversos profissionais.

Fazendo releitura do documento citado (objeto desse artigo) a partir de algumas contribuições teóricas, no qual percebemos na redação, diversas contradições e /ou conflitos conceituais, peculiares da política neoliberal vigente em nosso país pós anos 90. Fato que nos chamou atenção, às quais destacamos como ponto principal da nossa análise. Ou seja, explicitaremos e argumentaremos acerca de algumas divergências conceituais encontradas no texto citado, especificamente, sobre currículo - escritas por Moreira e Candau, identificadas no documento que, apesar de afirmar que [...] "se propõem a trabalhar concepções educacionais e a responder às questóes postas pelos coletivos das escolas, a buscar seus significados na perspectiva da reorientação do currículo e das práticas educativas" (2007 p. 9, grifo nosso), como proposta de reflexões para "um novo currículo", a todo instante traz elementos - termos e conceitos-, que seguem na linha das exigências da Unesco expressas no, "Relatório Jacques Delors" , como ficou conhecido o relatório para a Organização das Nações Unidas para a Educação, a Ciência e a Cultura (Unesco) da Comissão Internacional sobre a Educação para o século XXI, intitulado "Educação, um tesouro a descobrir". Sob a chancela da 
Unesco e contando com a participação de intelectuais de diversas partes do mundo, presidido por Jacques Delors, ex-ministro da economia e das finanças e ex-presidente da Comissão Europeia (1985-1995) a comissão delineou os princípios formativos para o cidadão do século XXI. Esse documento explicita a concepção de ensino, de aprendizagem e de desenvolvimento que vem norteando as práticas pedagógicas. A comissão foi formada oficialmente no ano de 1993. Em 1996, após inúmeras reuniões, encontros de grupos de estudo e várias outras atividades, finalizou os trabalhos e divulgou o relatório em seu livro: Educação: um tesouro a descobrir. Relatório para a Unesco da Comissão Internacional sobre educação para o século XXI (DELORS, 1998). Isto é verificado logo num primeiro momento quando é apresentado, de forma resumida, o eixo "Currículo, Conhecimento e Cultura", de Moreira e Candau, no qual apresenta elementos para reflexão sobre questões consideradas significativas no desenvolvimento do currículo nas escolas, analisando a vinculação entre a concepção de currículo e as de educação debatidas em um dado momento, com destaque para recente preocupação dos pesquisadores sobre as relações entre currículo e conhecimento escolar para as relações entre currículo e cultura. Apresentando à construção do conhecimento escolar como característica da escola democrática que reconhece a multiculturalidade e a diversidade como elementos constitutivos do processo ensino-aprendizagem.

Verificamos, portanto, a utilização dos termos "escola democrática", "multiculturalidade e a diversidade", como elementos constitutivos do processo ensino-aprendizagem. Esses termos estão presentes também constantemente no relatório Delors (1996). Isso nos faz pensar e reafirmar que o texto em análise, segue de forma contraditória à proposta inicial, expressando o que "dita" às políticas externas, ou seja; o que é mencionado inicialmente como "proposta para pensar um novo currículo a partir do coletivo, num processo democrático" entra em contradição com o que é imposto pelas agências internacionais, por exemplo, como condição para liberação de recursos (empréstimos), uma vez que os interesses do coletivo (base) são distintos dos interesses das políticas internacionais (materializada no Delors): Nesse sentido, o que os autores tratam como "novo currículo" de "novo" não tem nada, considerando à inexistência - verificada na nossa análise- de elementos que desvincule o texto do que está imposto pela política internacional. 
mantendo, portanto os preceitos do Estado Neoliberal.

Da forma menos ousada possível, procuramos na nossa análise, utilizarmos alguns dos pressupostos filosóficos presentes no ensino pensado com base na teoria histórico cultural. Procuramos trazer no desenvolvimento deste trabalho, análises conceituais dos autores, Carvalho, Galuch, Palangana, Moraes, Sforni, Saviani, fazendo o contraponto com o texto em questão, na tentativa de demonstrar, o quanto este texto expressa às políticas internacionais, como mencionamos acima.

Como metodologia escolhida foi realizada revisão bibliográfica e análise crítica do documento ministerial intitulado "Indagações sobre Currículo: currículo, conhecimento e cultura", Moreira e Cadau (2007). Realizamos estudo do texto trazendo discussões e reflexões de contribuições de diversos artigos publicados em livros e /ou diversos periódicos de textos de alguns autores que atuam na área da educação, e a partir disso as releituras de documentos na área como o conhecido "Relatório Delors", que trata dos quatro pilares da educação, para a Comissão Internacional sobre Educação para o século XXI da Unesco, coordenada por Jacques Delors; Referenciais Curriculares Nacionais para a Educação Infantil/ RCNEI; Os Parâmetros Curriculares Nacionais/PCN's para o ensino fundamental, e os Referenciais Curriculares para o Ensino Médio e as Diretrizes Curriculares para a Educação Básica do CNE, que serviram de aporte teórico e documentais para análise do citado documento ministerial "Indagações sobre Currículo: currículo, conhecimento e cultura".

\section{DESENVOLVIMENTO}

Neste tópico traremos reflexões dos autores Moreira e Candau (2007), presentes na redação do texto do documento ministerial, que corroboram nossa teoria de que, apesar de os autores proporem reflexões para "um novo currículo", acabam por reiterar o que já está posto pelos organismos internacionais.

Vejamos, no texto que os autores conceituam e fazem distinção entre "Currículo Planejado" - referindo-se às atividades organizadas pelas instituições escolares; e "Currículo Oculto" - referindo-se aos conteúdos que provocam 
efeitos não explícitos nos planos e propostas (ex. mensagens implícitas nas falas dos professores (as) e livros didáticos, na organização do mobiliário da sala etc.). E acrescentam que o currículo é o "coração" da escola, o espaço central onde todos atuamos, o que nos torna, nos diferentes níveis do processo educacional, responsável por sua elaboração. $O$ papel do educador no processo curricular é assim fundamental (MOREIRA; CANDAU 2007, p. 19, grifo nosso).

Após conceituarem currículo e suas diferentes formas de apresentação, os autores expressam - de acordo com citação acima-, há necessidade de os profissionais participarem dos debates para sua elaboração. Dessa forma, no nosso entendimento, os autores por meio de suas reflexões, acabam "responsabilizando" os professores (base) na elaboração dos currículos para atender o coletivo, ocultando a existência de toda uma influência externa nessas propostas, como se apenas a participação dos professores fosse importante para elaboração dos currículos.

Sabemos que as bases desses currículos já vêm prontas num plano vertical, - de cima para baixo -, e muitas vezes os professores da base, não sabem às origens dessas propostas e toda influência ideologia e política que atendem a interesses do capital internacional. Ou seja, independente da técnica ou abordagem adotada, os currículos são engessados e na prática não atendem aos anseios do coletivo, portanto responsabilizar os professores pela elaboração dos currículos torna-se nosso entendimento apenas "falácia".

Após o feudalismo, as relações sociais passam a serem fundadas nas relações de produção, de trabalho, de capital. Segundo Marx, nos séculos XVII e XVII, a burguesia firma-se como poder econômico, político e cultural, superando as relações feudais, primeiramente por meio da produção manufatureira chegando até a indústria.

As relações sociais no sistema capitalista são construídas a partir da ideia de consumo, lucro e poder. Desta maneira, a ideia de hierarquia é fundamental, uma vez que "[...] ela contribuí para deformar o trabalhador monstruosamente, levando-o a desenvolver uma habilidade parcial, à custa da repressão de um mundo de instintos e capacidades produtivas" (MARX, apud GALUCH; PALANGANA, 2008, p. 73). Apesar de essas autoras estarem fazendo referência à hierarquia da manufatura especificamente, acreditamos que muito contribui para nossa reflexão 
na contemporaneidade, uma vez que ao tratar a Escola como local de aprendizagem e desenvolvimento do intelecto, o coletivo existente passa a ter o objetivo comum: o conhecimento (professores ensinando e alunos aprendendo), mesmo que obedecendo a uma relação hierárquica. Porém, defendemos que essa relação hierárquica que têm objetivo comum (apropriação do conhecimento científico), se dê apenas na relação de ensino e aprendizagem (professor-aluno), o que não ocorre, numa sociedade neoliberal como à nossa.

Nesse sentido aqui cabe mais uma reflexão que contribui para nossa argumentação das contradições encontradas no texto em análise uma vez que os organismos internacionais contribuem para manutenção do capitalismo que têm uma relação hierárquica oposta à relação hierárquica estabelecida entre professor-aluno, cujo objetivo é comum (cooperação mútua para apropriação do conhecimento cientifico) e no capitalismo o objetivo é poder e lucro (acumulo de capital), influenciando diretamente na elaboração e materialização do currículo.

No Brasil, a "hierarquia" paradoxalmente "disfarçada de democracia", "dirige" a nação, por meio dos governantes com resultados contraditórios. As relações de poder e lucro (economia) se estabelecem na manutenção do capital, onde as agências internacionais e seus interesses internos, utilizando-se do discurso da flexibilização e compartilhamento da gestão, legitimam a participação de agentes externos para captação de recursos externos.

No nosso entendimento, de acordo com a política vigente, os professores são executadores de tarefas, apesar de o Estado "maquiar" o cenário afirmando a existência de "espaços de debates, discussão e construção pedagógica", os professores obedecem à lógica do mercado, reproduzindo o currículo previamente estabelecido em instâncias superiores, a fim de atenderem suas necessidades de sobrevivência. Isso é evidenciado numa educação "volátil, polivalente e superficial", denominada de "pedagogia da exclusão" na concepção de Saviani (2007). Segundo esse autor, antes de 1970 cabia à escola a preparação da mão de obra para o mercado que se expandia em direção ao pleno emprego, no entanto, após 1990, coube ao indivíduo o papel de exercer a capacidade de escolha, visando adquirir os meios que lhes permitam ser competitivo no mercado de trabalho.

Ainda sobre currículo, resumidamente os autores destacam a necessidade 
de que os alunos reconheçam a organização da vida social ou da sociedade na teoria contemporânea, com ênfase para a cultura. E na sequência, afirmam que: "a escola precisa preparar-se para bem socializar os conhecimentos escolares e facilitar o acesso do (a) estudante a outros saberes" (SAVIANI, 2007, p. 20, grifo nosso). Complementando uma afirmação anterior da mesma página sobre o assunto: [...] "a pluralidade pode propiciar o enriquecimento e a renovação das possibilidades de atuação pedagógica”. Como se estivessem na nossa análise-, substituindo o termo: "conbecimento" por "saberes", plurais.

Percebemos que a ideia defendida pelos autores, mesmo que de forma implícita, é utilizar de dois termos distintos como se fossem complementares - saber e conhecimento-, causando no leitor uma confusão e, portanto, a interpretação de que os saberes podem ser substituídos pelo conhecimento, como uma forma de possibilitar que o aluno reconheça e seja reconhecido, com base em sua diversidade [...]"cada um aprenda a compreender o mundo que o rodeia, pelo menos na medida em que isso lhe é necessário, para viver dignamente, para desenvolver as suas capacidades profissionais, para comunicar" (DELORS, 2001, p. 91)

Ora, os "saberes" não podem nortear o processo pedagógico, uma vez que entendemos "à escola como espaço de aprendizado do conhecimento científico", onde até consideramos que podem ser discutidos "saberes de forma empírica", desde que a partir daí se levantem questionamentos que propiciem a investigação, gerando a apropriação do conhecimento produzido nos diferentes campos científicos, seja na matemática, física, biologia, história etc. Porém, nunca se deve substituir o conhecimento transmitido na escola por saberes, isso seria um "retrocesso na ciência", no nosso entendimento, comprometendo a formação pedagógica desses alunos.

Essa ausência de teoria é verificada não só nas escolas, mas também nos cursos de formação superior, no qual trazemos para discussão a contribuição de Maria Celia Moraes, na obra "Recuo da Teoria", na qual destaca que "[...] a discussão teórica tem sido gradativamente suprimida ou relegada a segundo plano nas pesquisas educacionais, com implicações que podem repercutir, a curto e médio prazo, na própria produção de conhecimento na área" (MORAES, 2003, p. 153) e ainda acrescenta [...] "talvez a causa mais imediata desta marcha à ré intelectual esteja 
na definição e efetivação das próprias políticas educacionais, em níveis nacional e internacional, além do ethos neodarwinista que vem banalizando as universidades publicas brasileiras que agora devem ser de resultados" (MORAES, 2003, p. 154). Ou seja, nos cursos de formação e nível superior a teoria está cada vez mais "banida" diante da "precarização da educação" e por conseguinte formam professores para o nível do ensino básico "descompromissados com a teoria", com foco em resultados, capacitando o aluno minimamente para as exigências do mercado de trabalho atual com características neoliberais (imediatistas, focalista e privatista).

Diante do exposto acima, o professor passa a ser um "agente de extensão", no qual a prática passa a ser desprovida de reflexão, na perceptiva neoliberal. Como afirma MORAES: "Instaurou-se um mal estar epistemológico que, em seu profundo ceticismo e desencanto, motivou a pensar além de si mesmo, propondo a agenda que abrigou os pós-, os neo-, os anti-, e termos que tais, que ainda infestam a intelectualidade de nossos dias" (MORAES, 2003, p. 156). E complementa: "[...] à negação da objetividade aparece aqui associada à ideia de desintegração do espaço público, do fetichismo da diversidade”. (MORAES, 2003, p. 157).

Na sequência do texto analisado, ainda sobre currículo, resumidamente os autores falam que [...] "não há como inserir, nas salas de aula e nas escolas, os saberes e as práticas tal como funcionam em seus contextos de origem" (MOREIRA; CANDAU, 2007, p. 23), tornando-se, portanto, no entendimento dos mesmos, como "currículo descontextualizado" e exemplificam por meio das disciplinas de ciências e atividades desportivas "a limitação do conhecimento", considerando que o que está escrito nos manuais pedagógicos não são vivenciados, tornando-se distantes ou descontextualizados da realidade, sejam em experiências de laboratório científico, para disciplina de ciências, seja em locais de treinamentos de atletas profissionais na prática desportiva.

Tal reflexão corrobora com afirmação já citada anteriormente, quando os autores defendiam os "saberes na escola em detrimento do conhecimento". Porém, percebemos que os autores quando trazem o termo "descontextualizado", remetem a ideia de limitação. Pois defendem a complexidade, a subjetividade, a criticidade, as discussões... Acreditam que "[...] a descontextualização dos saberes e das práticas, que costuma fazer com que o conhecimento escolar dê a impressão de pronto, 
acabado, impermeável a críticas e discussões... o estudante acaba aprendendo simplesmente o produto, o resultado de um longo trajeto, cuja complexidade também se perde"(MOREIRA; CANDAU, 2007, p. 23).

Concordamos com a necessidade do ensino com práticas mais reflexivas para uma aprendizagem significativa. Porém, no nosso entendimento, isso não significa que o conhecimento clássico deva ser abolido por ser interpretado como "descontextualizado". A teoria é necessária e deve fundamentar o conhecimento, pois sem ela não há como criticar ou discutir. O termo "produto" utilizado pelos autores metaforicamente para tratar de conhecimento não pode ser substituído por saberes, pois dessa forma corre-se o risco de confundir ciência da não ciência. Ou seja, saberes e ciência não são a mesma coisa e, portanto, discernir entre um e outro é a condição necessária para uma educação qualitativa nas escolas. Isso não significa limitação, descontextualização ou qualquer outro termo utilizado para "justificar uma educação volátil e pouco consistente" que segue às exigências do sistema neoliberal.

De forma resumida, os autores afirmam que entendem a relevância e o potencial que o currículo possui de [...] "tornar as pessoas capazes de compreender o papel que devem ter na mudança de seus contextos imediatos e da sociedade em geral, bem como de ajudá-las a adquirir os conhecimentos e as habilidades necessárias para que isso aconteça" (MOREIRA; CANDAU, 2007, p. 21). Não concordamos com tal afirmação, pois no nosso entendimento, dessa forma, os autores colocam nas "mãos" do currículo e do indivíduo o poder de transformar o mundo por meio das suas habilidades. Excluindo nesse contexto a relação existente e concreta do capitaltrabalho e todas as suas implicações, assim como "as estratégias" de manutenção no acúmulo do capital, evidentes do Sistema Neoliberal na Política Educacional vigente.

Defendemos, portanto, a ideia de que o currículo deve ser capaz de possibilitar que o indivíduo abstraia o conhecimento, do qual sairá da condição de ignorância. Porém, não necessariamente isso o responsabiliza para transformar a realidade com base nas suas habilidades. Ou seja, no nosso entendimento, o discurso de "babilidades e competências é focal, raso e superficial". Uma vez que, dessa forma, impõe unicamente ao indivíduo "o poder" de transformar sua realidade. Alegando, portanto que, se o indivíduo tiver competência e habilidade suficiente 
é capaz de abstrair o conhecimento do currículo e transformar sua realidade, excluindo desse contexto a questão social, expressão do capitalismo presente na sociedade contemporânea.

Enquanto a produção taylorista/fordista necessitava de sujeitos disciplinados, com capacidades para a execução de tarefas repetitivas, a produção de base toyotista requer sujeitos que executam múltiplas tarefas e encontrem soluções para diferentes problemas. Todavia, são mudanças substanciais no processo de produção, mas não na lógica objetiva das relações sociais da sociedade, quer dizer, os princípios que fundamentam a sociedade capitalista - a produção para o lucro - não foram alterados. Os objetivos da formação, porém, não se diferem daqueles postulados pela produção taylorista/fordista, pois ambas as formas de produzir buscam a formação capaz de tornar os sujeitos adaptáveis às necessidades da sociedade que, por sua vez, continua regulada por relações entre classes antagônicas, sem a preocupação com o desenvolvimento integral de todos os seres humanos (GALUCH; SFORNI, 2011, p. 58-59).

Precisamos, portanto, estar atentos à lógica que legitima a sociedade capitalista e suas "estratégias de manutenção", como essa de atribuir ao individuo a capacidade de transformação, por meio de suas habilidades, materializando esse discurso no currículo atual.

Outro ponto importante apontado pelos autores que merece nossa análise está baseado na "subordinação dos conhecimentos escolares", no qual propõem uma reflexão para os educadores sobre o uso de novas tecnologias e o que estamos fazendo para aproveitá-las, trazendo a afirmação de que "os estudantes conseguem queimam etapas" (2007, p. 24), referindo-se às etapas da psicologia do desenvolvimento e que talvez estejamos subestimando o jovem, uma vez que ele é capaz de demonstrar por meio do uso da tecnologia sua capacidade técnica para além da sua idade. Porém, questionamos isso de outro ângulo: Será que essa capacidade técnica acompanha a cognitiva? Será que não é nocivo esse "queimar etapas"? Será que essas novas tecnologias o fazem pensar, ou são meros executadores de tarefas, nos quais às funções "Control Alt." e" Control Del" são essenciais?

Tais questionamentos nos fazem voltar ao tempo e indagarmos, de que tempo mesmo estamos falando? Paradoxalmente estamos diante de "novas tempos, 
novas tecnologias, novos agentes" $\mathrm{X}$ "velhos conceitos e formas repetidas de modos de produção". Ou seja, o que deu lugar à mercantilização, e manufatura industrialização-, com proletários utilizando-se "suas habilidades" a favor do capital, hoje é repetido por meio do livre mercado e concorrência desleal, no qual se exigem novamente que o trabalhador esteja constantemente atualizado, com o domínio das novas tecnologias, novos idiomas etc.

Cabendo, portanto ao trabalhador mediante suas habilidades se fixarem no mercado (setor de serviços e demais setores) e, para isso, há necessidade de resolver questões práticas, em que questões filosóficas - de pensamento- infelizmente, não têm espaço. Dessa maneira, o trabalhador torna-se "alienado" e "refém do imediatismo", do fazer; agir; cumprir. Ou seja, adaptáveis às necessidades atuais da sociedade capitalista. Sem possibilidade para reflexão e, portanto, para análise da realidade à que estão submetidos.

[...] Se por um lado, a divisão do trabalho e a especialização de funções aprimoram determinadas habilidades, por outro lado, as ações repetitivas e uniformes dispensam a capacidade de compreensão e análise, tanto do produto, de cuja realização o sujeito participa, como das condições a que está submetido... (GALUCH; PALANGANA, 2008, p. 74, grifo nosso).

Fazendo relação com o texto analisado e a defesa dos autores para o "uso da internet no acesso a informações e saberes de modo não linear" (GALUCH; PALANGANA, 2007, p. 24), fica claro que para os autores há necessidade dos professores aproveitarem essa "nova tendência" de transmissão de saberes, por meio do uso de novas tecnologias.

Discordamos deste ponto de vista, por acreditarmos que se trata de uma estratégia de manutenção da ordem, por meio da alienação. Uma vez que os estudantes ao manterem-se como "executadores de tarefas mecânicas no mundo virtual", tornam-se "seres alienados do mundo real", sinalizada em outras palavras por Galuch e Palangana, na citação acima.

Outra questão colocada pelos autores do texto analisado, é que o currículo é entendido como conjunto de práticas que produzem significados, relacionando-o mais uma vezà cultura. Porém, os autores abrem espaço questionando os profissionais 
da atualidade para a forma que lidam com essa definição de cultura e currículo nos espaços escolares. Os autores destacam o desafio de lidar com [...] "as diferenças derivadas de dinâmicas sociais como classe social, gênero, etnia, sexualidade, cultura e religião que tem contaminado nosso currículo" (GALUCH; PALANGANA, 2007, p. 29). Em seguida, questionam como articular currículo e multiculturalismo, explicitando como estratégias das escolas à utilização das disciplinas de história e geografia para trabalhar essas questões.

Entendemos que essas práticas acabam por focalizar e fragmentar o conhecimento. Quando se dividem esses grupos, o todo fica comprometido e fragilizado, e as lutas que antes eram de classes passam a serem de grupos, não atingindo o todo. Segundo Carvalho, "[...] ao se negar sua força totalizadora e homogênea, em nome da celebração da diversidade, relacionam-se as diferenças à simples pluralidade, sem se considerar que elas são parte construtiva das relações capitalistas, cujas marcas são a desigualdade e a exclusão" (CARVALHO, 2010, p. 35).

Outro aspecto trabalhado no texto "Indagações Sobre o Curriculo", Moreira e Candau (2007) - objeto de nossa análise-, é a necessidade de ruptura do "daltonismo cultural e da visão monocultural" na dinâmica escolar. Fazendo um paralelo o relatório Delors, percebemos semelhanças nos textos, que propicia refletirmos que ambos defendem a mesma linha de pensamento, uma vez que tanto o texto analisado quanto o Delors - defendem o multiculturalismo buscando no nosso entendimento a coesão social das diferenças. "[...] A educação deve possibilitar aos indivíduos a garantia de coesão na realidade social e de percepção das mudanças globais em curso. Para isso os sujeitos precisam ter clareza de sua identidade nacional sustentada em bases culturais, cabendo aos institutos de educação, entre eles as escolas, fornecer essa resposta. Em vista disso, a educação deve transmitir, de fato, de forma maciça e eficaz, cada vez mais saberes e saber-fazer evolutivos, adaptados à civilização cognitiva, pois são as bases da competência para o futuro" (DELORS, 1996, p. 89).

Talvez de forma pouco mais ousada na nossa análise, aliamos ao sentido de coesão social outro aspecto que ela traz consigo:- "o de superar as desigualdades, talvez as naturalizando" (trataremos disso na conclusão).

Contraditoriamente a essa "naturalização"- percebida nas entrelinhas-, os 
autores expõem a "necessidade de repensar atitudes, no sentido de desnaturalizar estereótipos e verdades [...] reescrever o conhecimento usual tendo-se em mente as diferentes raízes étnicas a partir de diferentes pontos de vista (GALUCH; PALANGANA, 2007, p. 32)". Ora, o conhecimento científico não é construído com fundamentos de "ponto de vistas", pelo contrário; é algo testado e comprovado. Não se pode suprimilo, substituindo-o por "pontos de vista distintos" ou vulgo "achismo", caindo na armadilha da subjetividade de que nele "tudo pode" por ser "terra de muitos ou de ninguém, ao mesmo tempo".

\section{CONSIDERAÇÕES FINAIS}

Após análise do texto "Indagações Sobre o Currículo" Moreira e Candau (2007), consideramos que os autores têm em seus discursos propostas de pensar a educação, o conhecimento, a escola, o currículo a serviço de um projeto de sociedade democrática justa e igualitária. No qual, afirmam a todo instante a necessidade de respeito à diversidade para superação das desigualdades. No nosso entendimento, estamos diante de uma questão paradoxal, uma vez que consideramos diversidade e desigualdade, como categorias distintas, no qual a segunda para ser "combatida" depende que a primeira seja reconhecida como diferença. Ou seja, para combater a desigualdade social é necessário que reconheçamos que as diversidades como diferenças, provocando a "desarmonia" e /ou a "incoesão social", pois só se combate o que se é contrário. É preciso que tenhamos claro que o "respeito à diversidade e/ou diferença" no sentido de coesão social não é sinônimo de "luta das desigualdades", pelo contrário, ela é possibilidade de naturalização das desigualdades, corroborando com a lógica neoliberal.

Os vários autores contemporâneos, que trouxemos nessa discussão, apresentam reflexões sobre essa temática, são unânimes na crítica que fazem sobre a atual pedagogia como expressão das exigências das políticas econômicas internacionais para manutenção do capital. Isso é verificado, principalmente, quando citam a necessidade substancial do reconhecimento das diferenças presente nos documentos da Unesco, em combate ao racismo, à intolerância e ao 
preconceito. Segundo Carvalho (2010, p. 18), o propósito é o de criar condições para um "desenvolvimento humano mais harmonioso e equitativo, de modo a aliviar a pobreza, enfrentar a exclusão socioeconômica, amenizar as opressões e os conflitos, quer global quer interno a uma sociedade, enfim, atingir a coesão social e a segurança e paz internacional entre sociedades diversificadas". É nesse sentido que se destaca na atual pedagogia a necessidade de aliar "currículo e cultura", a fim de promover a compreensão mútua entre os povos e, dessa forma, legitimar o sistema econômico, com a fragmentação da luta política, dando lugar à política de identidade.

Não possuímos uma "identidade nacional" e, portanto, não podemos tomar "consciência de uma identidade cultural", sugerida nas entrelinhas, pelos autores (Moreira e Candau) do texto analisado com a intrínseca naturalização da diversidade e, portanto, as diferenças numa tentativa de homogeneizar essas diferenças, substituindo-as por diversidade no discurso neoliberal. Diferente disso é necessário, pois, tratarmos essa identidade nacional como identidade de classes, para o combate ao sistema.

\section{REFERÊNCIAS}

CARVALHO, E.J.G. Educação e Diversidade Cultural. In: CARVALHO, E.J.G.; FAUSTINO, R.C. Educação e Diversidade Cultural. Maringá: EDUEM, 2010, p. 17-54.

DELORS, J. (Org.). Educação um tesouro a descobrir: relatório para a Unesco da Comissão Internacional sobre Educação para o Século XXI. 7. ed. São Paulo: Cortez, 2012.

GALUCH, M.T.B.; PALANGANA, I. C. Experiência, cultura e formação no contexto das relações de produção capitalistas. Intermeio (UFMS), v. 15, p. 71-87, 2008.

GALUCH, M.T.B.; SFORNI, M.S.F. Interfaces entre políticas educacionais, prática pedagógica e formação humana. Práxis Educativa, Ponta Grossa, v. 6, n. 1, p. 55-66, jan./jun. 2011. Disponível em: < http://www.revistas2.uepg.br/index.php/ praxiseducativa/view/1862/199. 07 maio 2018 
LIBÂNEO, J.C. O dualismo perverso da escola pública brasileira: escola do conhecimento para os ricos, escola do acolhimento social para os pobres. Educação e Pesquisa, São Paulo, v. 38, n. 1, jan/mar, 2012, p.13-28. Disponível em: < http:www. scielo.br/pdf/ep/v38n1/aop323.pdf>. 07 maio 2018

MORAES, M. C. M. O Recuo da Teoria. In: MORAES, M.C. M. (Org.). Iluminismo às avessas: produção de conhecimento e políticas de formação docente. Rio de janeiro: DP\&A, 2003. p.151-167.

MOREIRA, A. F.; CANDAU, V. Indagações sobre Currículo: currículo, conhecimento e cultura. Brasília: Ministério da Educação, Secretaria de Educação Básica, 2007. Disponível em: < http://portal.mec.gopv.br/seb/arquivos/pdf/Ensfund/indag3.pdf > . Acesso em: 07 maio 2018.

SAVIANI, D. O Neopositivismo e suas variantes: neo-ecolanovismo, neoconstrutivismo, neotecnicismo (1991-2001). In: SAVIANI, D. História das ideias pedagógicas no Brasil. Campinas, SP: Autores Associados, 2007.

Recebido em: 09/04/2018 Aceito em: 16/10/2018 